\title{
Probing Marine Systems with Ribosomal RNAs
}

\author{
By Stephen Giovannoni and S. Craig Cary
}

\begin{abstract}
$\mathrm{T}$ HE ADDiTion of molecular genetic tools to oceanographic toolboxes began with a pronounced emphasis on ribosomal RNAs (rRNAs). Already these molecules have been used to detect and examine the abundance of novel bacterioplankton species, to study host specificity and diversity among zooxanthellae, to identify the chemolithotrophic symbionts of hydrothermal vent metazoans, and to study evolutionary relationships among a myriad of species, including the most primitive metazoans. Here we review some present and projected applications of this molecule to oceanographic science and attempt to explain its preeminence in the emerging field of molecular oceanography.
\end{abstract}

\section{Why Ribosomal RNAs?}

Of the 1,500 or so genes in bacterial cells (and many more in eukaryotes) rRNA genes have been a focus of attention because of their unusual properties. Most genes are coded information specifying the sequence of amino acids for proteins. Ribosomal RNA genes (rDNAs) specify nonencoded, structural RNA products, which are direct copies of the gene. These products, the rRNAs, are parts of a much larger structure, the ribosome. Ribosomes are abundant cellular components filling the essential function of protein synthesis. The abundance of ribosomes is itself a persuasive argument for their use-rRNAs may constitute $20 \%$ of the dry weight of an actively growing bacterial cell. Furthermore, cells regulate ribosome synthesis in response to growth rate, suggesting that crucial information about the growth status of cells might be obtained by studying specific rRNA content.

In the 1970s Carl Woese and colleagues began to use ribosomes for comparative studies among bacteria (Woese, 1987). They were an obvious choice, in part because of their abundance, but also because of another fortunate feature: they are very highly conserved, which makes them useful for comparing organisms that speciated during the Pre-

S. Giovannoni and S.C. Cary, Department of Microbiology, Oregon State University, Corvallis, OR 97331, USA. cambrian. This feature has occasionally been a disappointment for those interested in recent evolutionary events. However, for the study of distantly related taxa, the conservative nature of rRNAs, and the fact that they are not laterally transferred among organisms, has made them useful for tracing evolutionary relationships with molecular phylogenetic techniques. Indeed, different parts of rRNAs, and different RNAs, accumulate mutations at different rates, making them even more versatile tools.

Bacterial ribosomes contain three rRNA types in equimolar amounts: $23 \mathrm{~S}(\sim 2,400$ nucleotides in length), 16S (1,540 nucleotides), and 5S (120 nucleotides). The eukaryotic counterparts of these molecules are slightly larger. The rRNA genes are arrayed on chromosomes in a specific order within transcriptional units called operons (Fig. 1; Brosius et al., 1981). The most conserved of the genes and the most widely used is the 16S rRNA. Large subunit rRNAs, which are about 5-10 times more variable, are coming into wider use for examining relationships among closely related taxa. Probably the most variable parts of rRNA operons are the internal transcribed spacers (ITS), which are now the focus of investigations centered on biogeographical questions.

The extensive use of rRNAs as molecular chronometers for phylogenetic studies led to the development of large computer data bases and a revised understanding of evolutionary relationships among bacteria. protists, and invertebrates. This progress has been fueled by the rapid development of new techniques, such as the polymerase chain reaction (PCR), which brought molecular studies within reach of scientists not steeped in the arcane discipline of nucleic acid chemistry. Polymerase chain reaction, which won Kary Mullis a Nobel prize in 1993. is a method for synthesizing millions of copies of a gene. For a review of molecular biology relevant to oceanography, see Falkowski and LaRoche (1991). The result of this tremendous research effort is summarized in the computer files of the RNA DataBase Project (RDP), which now includes about 1,400 sequences (Olsen et al., 1991).
... the conservative

nature of rRNAs,

. . has made

them useful for

tracing evolutionary

relationships with

molecular phyloge-

netic techniques. 


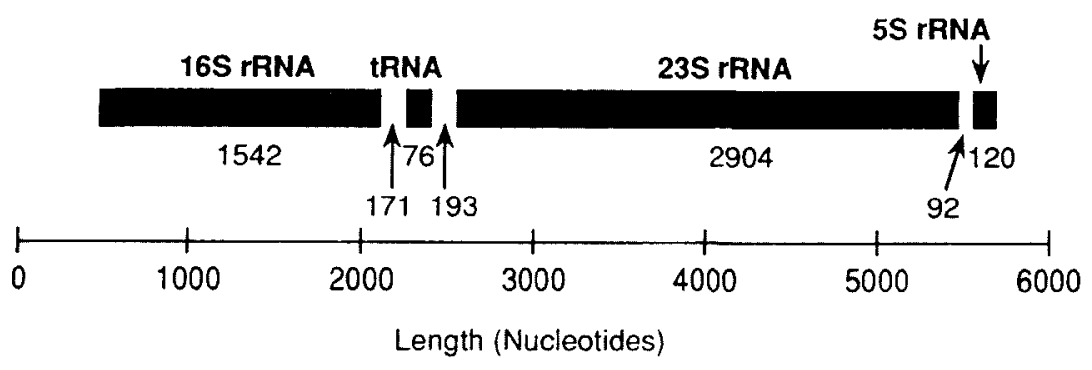

Fig. 1: The rrnB operon from the chromosome of Escherichia coli (Brosius et al., 1981). Functional ribosomal RNA and transfer RNA genes, all of which code for structural RNA products, are shown in filled black. Numbers indicate lengths in nucleotides. The unfilled segments are internal transcribed spacers (ITS). which are highly variable, in contrast to the structural genes involved in protein synthesis, which are highly conserved. The ITS regions have no known function, other than to link rRNAs together during the early stages of rRNA synthesis.

In addition to their use for molecular phylogenies, rRNAs and rDNAs can be hybridized to DNA probes for the quantitative detection of organisms in natural samples (Stahl et al., 1988; Giovannoni et al., 1990). Hybridization is a chem- ical reaction in which noncovalent hydrogen bonds are formed between two strands of DNA or RNA that have complementary sequences. The design of hybridization probes takes advantage of an important property of molecular biology that has made it a productive science: the informational quality of the data. Sequence data bases can be scanned by any investigator to reveal short "domains"-regions 15-30 nucleotides in lengthwhich uniquely identify a gene of interest (Fig. 2). It is important to note that any 20-base polynucleotide will occur on the average only once in $10^{12}$ base pairs of random sequence. Interactions between base pairs different from those originally defined by Watson and Crick can make probes less specific than these numbers might suggest. An example would be the pair guanine-uracil, instead of the canonical guanine-cytosine. Nonetheless. short DNA molecules, oligonucleotides, can be made that will pair, by hydrogen bonding. with very high specificity to unique target sequences. The DNA molecules are made on automated DNA synthesis machines. Hypervariable domains of small subunit rRNAs, in which there are only two or three variations in nucleotides between bacter-

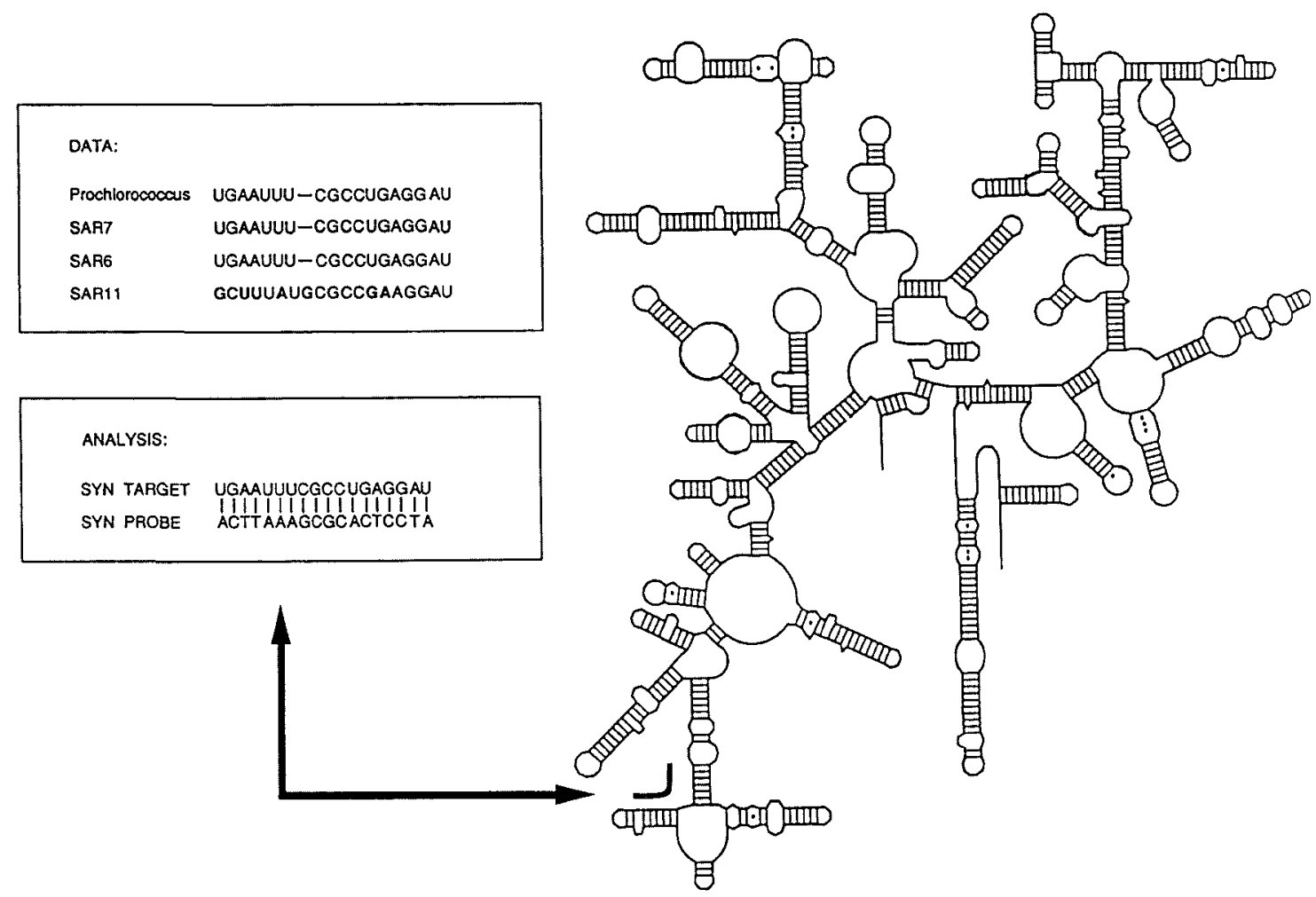

Fig. 2: A simplified example of the procedure used to design phylogenetic DNA probes from data bases of $16 S$ rRNA sequences. The I6S $r R N A$ is a mosaic of conserved and variable regions. In this example, a small sequence domain is identified which is shared by autotrophic picoplankton (marine Synechococcus and Prochlorococcus), but differs from homologous regions of the SAR11 gene (Britschgi and Giovannoni, 1991). SAR7 and SAR6 are marine Synechococcus and Prochlorococcus genes, respectively, which were cloned directly from seawater. SARII is an abundant bacterioplankton group that is known only genetically. The target site for the probe is indicated on the $16 S$ rRNA structural model. Actual analysis uses computers and a data base of $>1,000$ nucleotide positions from 500 organisms. 
ial subspecies, can be used for accurate identification with DNA probes. Likewise, other sequence domains with varying degrees of evolutionary conservation can be used to design probes of species, genus, family, phylum, kingdom, or universal specificity (Giovannoni et al., 1988). Either rRNAs, or the genes themselves, can be used as targets for probes.

The remainder of this review will focus on the use of rRNAs as genetic markers for the identification of microorganisms in marine systems. Two main applications of this approach so far have been studies of bacterioplankton diversity and bacterial symbionts of invertebrates. In most cases, more variable molecular structures, such as mitochondrial DNA, are proving useful for population genetic studies of higher organisms.

\section{Bacterioplankton Diversity}

Ribosomal RNAs are providing both information on bacterioplankton phylogenetic diversity and taxon-specific nucleic acid probes. These probes can be used experimentally to establish the identity of cultured strains and to study the spatial and temporal distributions of microbial taxa in the oceans. A major strength of this approach is that it can identify organisms that have not been grown in culture (Olsen et al., 1986). These investigations are testing a premise favored by some members of the scientific community: that many bacterioplankton species have not been defined in taxonomic, phylogenetic, or experimental terms.

Although bacterioplankton are widely recognized as important agents of biogeochemical change in marine ecosystems, microbial communities are often regarded as "black boxes." Little progress has been made in developing predictive theories explaining planktonic processes in terms of the activities of specific microbial groups. In most cases, it has been difficult even to measure the abundance of significant bacterioplankton species. The principle exceptions have been photoautotrophic* picoplankton, which can be detected reliably by the autofluorescence of their light-harvesting pigments, and some heterotrophic bacteria, which are easily cultivated. In question have been the abundant cells that are not autofluorescent and do not form colonies on standard microbiological media.

Uncertainty about bacterioplankton identity stems from a simple observation: in the photic zone bacterial cell counts measured by epifluorescence microscopy vary from $0.2 \times 10^{\circ}$ to $2 \times 10^{6}$ cells per $\mathrm{ml}$, but viable cell counts on bacteriological media are typically three orders of magnitude lower (Kogure et al., 1979). These observations could result from many cells of a given species failing to form colonies (low plating efficiencies),

* Photoautotroph, an organism able to use light as its sole source of energy and $\mathrm{CO}_{2}$ as its sole source of carbon. but could also be a consequence of the failure of some species to grow on bacteriological media. Many eukaryotic phytoplankton species have not been cultivated because of their tricky requirements for growth (Brand, 1987). This may be true also for bacterioplankton.

Proponents of a competing theory have argued that bacterioplankton are ordinary marine bacteria that have entered a viable but nonculturable state as a consequence of nutrient deprivation (Rozak and Colwell. 1987). These physiological arguments are somewhat difficult to reconcile with the wider body of ecological theory emerging from studies of the microbial loop, which holds that bacterial production is relatively high in the open ocean (Azam et al., 1983). Radioactive thymidine uptake studies and growth estimates extrapolated from protozoan grazing have lent support to the notion that in situ division times for bacterioplankton are on the order of hours or days, although concerns about the universality of thymidine-uptake mechanisms in bacteria have added an element of uncertainty (Hollibaugh, 1988). The remarkably small size of oceanic bacterioplankton has also figured in the debate, the question being whether this is the normal state of bacterioplankton or a consequence of nutrient limitation. Studies by Ferguson and co-workers suggested that the addition of nutrients to seawater samples caused a shift in the average size of bacterioplankton, but failed to establish whether this was due to shifts in physiology or species dominance (Ferguson et al., 1984). Lee and Fuhrman (1991) used genomic DNA/DNA hybridization to examine changes in the composition of confined bacterioplankton communities and found that no changes occured within 24 hours, although the number of culturable bacteria increased significantly.

Analyses of 16 SDNAs cloned "at random" from oceanic bacterioplankton populations have added a new dimension to the debate by providing a less biased list of the species present in natural populations. Clone libraries from the National Science Foundation Joint Global Oceans Flux Studies Program (JGOFS) ALOHA station in the central Pacific, the Sargasso Sea, and several depths in the Western California current have been examined (Giovannoni et al., 1990; Schmidt et al., 1991; Fuhrman et al., 1993). Although the cloning approaches used by these workers were different, they all relied upon analyses of genes cloned directly from bacterioplankton biomass without cultivation. In each case the selection of single genes from a complex genomic DNA mixture was accomplished by the ligation reaction used in gene cloning, which splices single pieces of DNA into vector molecules for subsequent isolation and replication. Gene cloning procedures potentially can involve biases that are not fully understood, but the biases are much less encumbering than those imposed by microbial cultivation requirements.
. . bacterioplankton

are widely recognized

as important agents

of biogeochemical

change in marine

ecosystems, . . . 
The results have been startling. Comparisons of the unknown genes to data bases of 16S rRNAs from cultivated species have revealed little overlap. Furthermore, many of the novel microbial taxa detected so far were found in both the Pacific and Atlantic samples, suggesting that they are broadly distributed. The genetic markers from these samples fall into several phylogenetic groups. A majority of the clones belong to the cyanobacteria and proteobacteria, although Grampositive bacteria and flavobacteria were also detected. In separate work, novel Archaea (archaebacteria) genes have been found also (DeLong, 1992: Fuhrman et al., 1992). A general phylogenetic tree showing relationships among these groups is shown in Figure 3. The phylum Cyanobacteria includes all known cells and eukaryotic organelles capable of photolytically oxidizing water. The phylum Proteobacteria, which includes primarily Gram-negative bacteria of the $\alpha, \beta, \gamma$, and $\delta$ subdivisions, is physiologically diverse. Most common strains of marine prokaryotes, including the genera Photobacterium, Vibrio, Oceanosprillum, and Alteromonas, are members of the $\gamma$ subdivision of the Proteobacteria. The Ar-

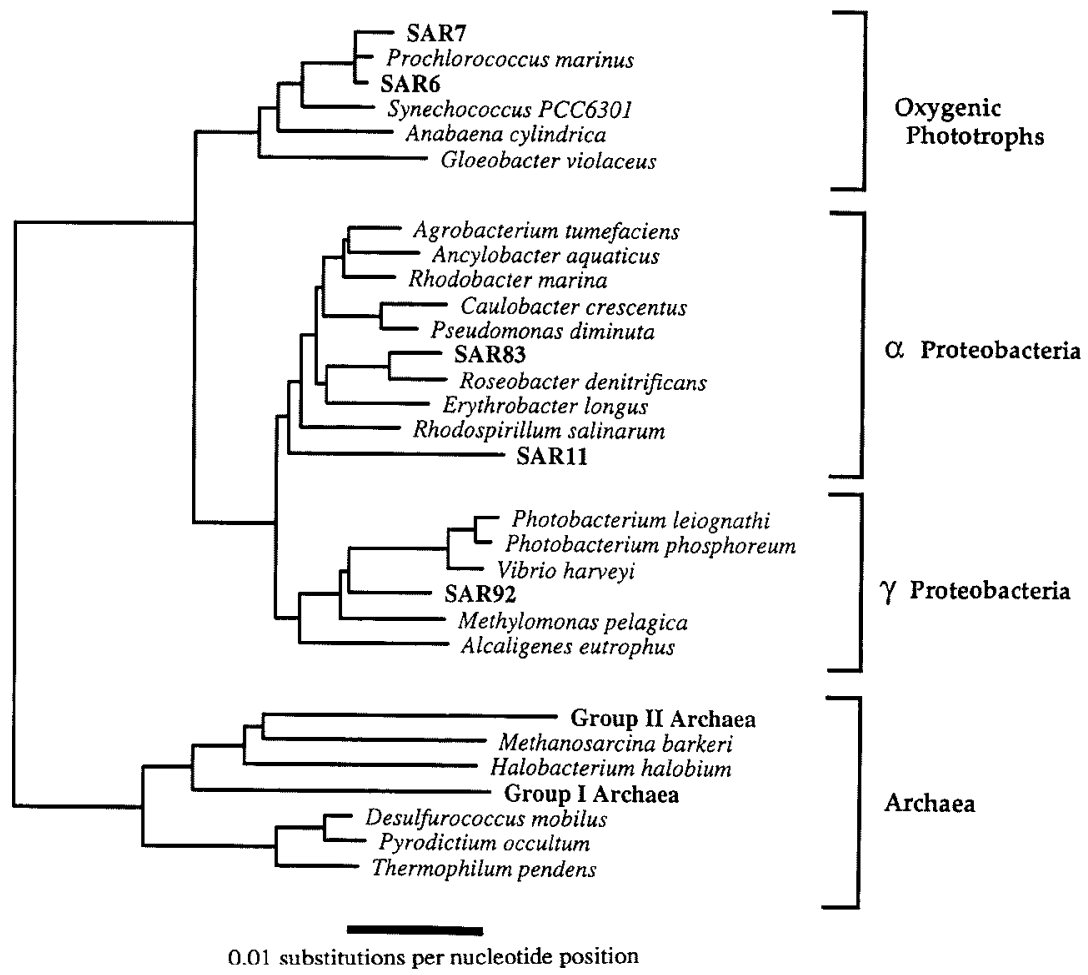

Fig. 3: Evolutionary comparisons of picoplankton 16-S rDNAs to genes from cultured organisms. Genes with the prefix "SAR" were cloned directly from a surface water bacterioplankton population collected at Hydrostration $S$ in the Sargasso Sea. Otherwise, the names refer to cultured species. The genes from group I and group II Archaea shown here were cloned from coastal water samples (DeLong, 1992), but similar genes were cloned from mesopelagic water samples in the open Pacific by Fuhrman et al. (1992, 1993). This phylogenetic tree was inferred by a distance-matrix method. chaea, previously known as the Archaebacteria, are a domain of prokaryotes clearly separate from the Bacteria.

The "cyanobacterial" sequences recovered form a cluster of high similarity, which includes the sequences of known marine Synechococcus sp. However, multiple closely related but unknown lineages were observed. This finding is consistent with the observation that immunofluorescence detection with antibodies to surface antigens of cultivated marine Synechococcus sp. can account for only 20\% of the Synechococcus cells (Campbell et al., 1983). When the $16 \mathrm{~S}$ rRNA sequence of a cultivated prochlorphyte (Prochlorococcus marinus) was added to the data base, it was found to be very similar to one branch of unknown "marine Synechococcus" genes cloned from the open ocean (Urbach et al., 1992). This surprising result underscored the substantial phenotypic diversity that can be found among closely related $16 \mathrm{~S}$ rRNA genes and further suggested that some of the additional diversity within the marine Synechococcus gene cluster might be uncultivated prochlorophyte lines.

The observation of abundant $\alpha$ proteobacterial 16S rRNA genes in the bacterioplankton community was not a complete surprise, since many members of this diverse physiological group are "oligotrophic" heterotrophs-aerobic bacteria able to subsist on dilute carbon sources. However, $\alpha$ proteobacteria had never been considered an important component of bacterioplankton, and rarely have $\alpha$ proteobacteria been used as models for marine microbial processes, most instead being focused on marine isolates of $\gamma$ proteobacteria. Among the many novel $\alpha$ proteobacterial genes observed, two clusters of particular abundance, the SAR11 and SAR83 groups, emerged. The physiology of the SAR11 cluster remains entirely unknown. The physiology of the SAR83 cluster also is unknown; however they are phylogenetically allied to a known marine bacterium, Roseobacter denitrificans. Roseobacter is capable of photoheterotrophic $\dagger$ growth, using bacteriochlorophyll as a light-harvesting pigment. We have been unable to detect bacteriochlorophyll $a$ in surface waters at the Bermuda Atlantic Time Series (BATS) station, suggesting that the SAR83 cluster are not photoheterotrophs.

In separate work, DeLong (1992) and Fuhrman et al. (1992) have found rDNA markers for a novel group of Archaea (archaebacteria) in coastal and oceanic midwater. Recently, we have found that these lineages account for a majority of $16 \mathrm{~S}$ rDNAs in the upper mesopelagic zone at the BATS station in the Sargasso Sea (N. Adair and S.J. Giovannoni, unpublished observations). The

$\dagger$ Photoheterotroph, an organism using light as a source of energy and organic material as a source of carbon. 
unknown organisms belong to the Crenarchaeota-a "kingdom" composed of mainly thermophilic species. Fuhrman et al. (1992) recovered the genes from samples collected in the Pacific Ocean on the western side of the California Current at depths of 100 and $500 \mathrm{~m}$ using a general PCR cloning technique. DeLong (1992) has detected similar lineages, as well as a separate gene cluster apparently related to the methanogenic Archaea, in coastal samples from the Santa Barbara Channel, the Oregon Coast, and Woods Hole. His approach used specific PCR primers capable of amplifying rare Archaea genes from a complex population. The observation of Crenarchaeota lineages in cold water habitats is perplexing. Huber et al. (1990) reported recovering viable Crenarcheota from seawater in the vicinity of a volcanic eruption. However, the unknown Crenarchaeota $16 \mathrm{~S}$ rDNAs recovered from seawater have only a moderate percentage of guanine and cytosine residues. These bases help to stabilize nucleic acid duplex structures and are found at high percentages in the $16 \mathrm{~S}$ rDNAs of extremely thermophilic species.

The above studies made no attempt to discriminate between freely suspended bacteria and those attached to particles. DeLong et al. (1993) specifically addressed the problem of particle-attached bacteria by examining marine snow collected in the California Bight. Comparisons of rDNA libraries from marine snow and seawater were dramatic; there was no overlap between the two populations. Moreover, the majority of the particle-attached species were related to the microbial genera Planctomyces, Cytophaga, and Flavobacterium, which are well known for their ability to associate with surfaces. These data are from a single set of samples. If further work supports generalization from these early results with phytodetrital particles, then the common view that bioluminescent marine enteric bacteria (Vibrio and Photobacterium sp.) are important in marine microaggregate formation may be called into question.

The above discoveries have created a rich backdrop of information and hypotheses about bacterioplankton diversity, but as yet the questions arising are more numerous than the answers. For example, why are so few gene sequences from cultivated species detected in natural populations? It is likely that more of the bacterioplankton species abundant in nature will be found in culture collections as methodical DNA probe screening approaches are applied. Yet it may also prove true that common laboratory culture conditions are inimical to the growth of some important bacterioplankton species. Prochlorococcus, which was first detected by fluorescence-activated flow cytometry, was only isolated into culture after a difficult and prolonged effort.

The strategy of our genetic investigations of bacterioplankton diversity at the (BATS) is outlined in Figure 4. The purpose of the time-series study at BATS, which is supported by the $\mathrm{Na}$ tional Science Foundation JGOFS, is to focus multiple scientific investigations on seasonal changes at a single oceanic site located in the Sargasso Sea near Bermuda. Initial molecular investigations of this type were limited to a few samples because they relied on large water volumes (>100 liters) collected by tangential flow or other specialized filtration methods. Advances in nucleic acid purification and analytical techniques are permitting smaller water samples collected by standard oceanographic methods ( 12 liters from Niskin rosettes) to be used in routine analyses.

An example of the results from this investigation (Fig. 5) shows the distribution of prochlorophytes and SAR 11 I6S rDNAs in the upper 250 meters of the water column during August when the water column was highly stratified. The data indicate that the SAR 11 cluster is most abundant in the upper euphotic zone, whereas at the time of this sampling prochlorophytes were most abundant near the deep chlorophyll maximum.

Recently, we detected a lineage of genes related very closely to the SAR 11 cluster. They were found in a $16 \mathrm{~S}$ rRNA gene library cloned from 250 meters in the Sargasso Sea. These genes are most abundant in the upper mesopelagic zone, suggesting that marine bacteria may include subspecies with depth-specific distributions. For the present, we refer to this new lineage as DeepSar 11.

In the same 250 -m clone library we also detected an unusual 16S rRNA gene lineage belong-

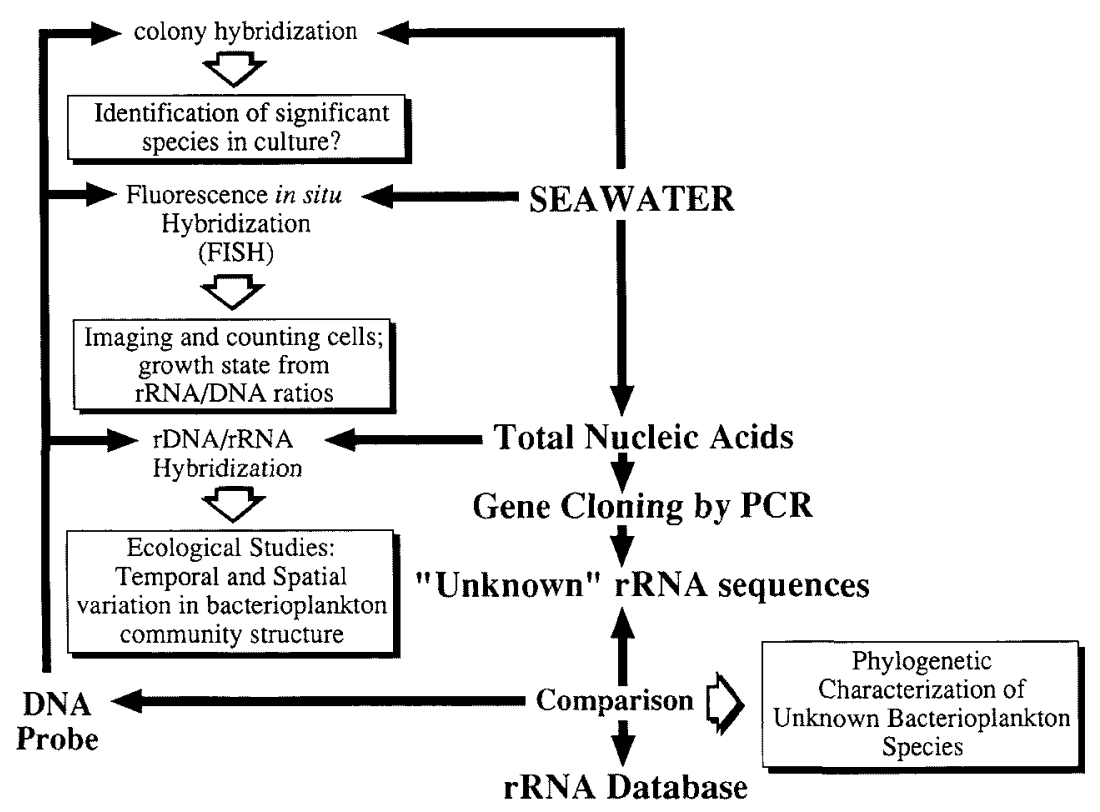

Fig. 4: Schematic outline of the strategies used for genetic investigations of bacterioplankton diversity. These approaches do not rely on cultivation, but instead focus on natural populations of cells obtained by filtration. 


\section{. . symbionts \\ . . are frequently}

difficult or impossible

to culture free from

their host environment. ing to the Chloroflexus/Herpetosiphon phylum (Rappé et al., 1993). This phylum is one of the early evolutionary branches of the Bacteria. No members of this group were known previously from the open ocean. It is particularly interesting that this $16 \mathrm{~S}$ rRNA gene reaches a maximum in abundance just beneath the euphotic zone. Collectively, these data suggest that surface, midwater, and subeuphotic zone populations differ significantly in species composition. Future investigations will be aimed at understanding the physical. chemical, and biological factors which control the growth of these populations.

\section{Marine Bacterial Symbiosis}

Ribosomal RNA directed probe technology has proven particularly useful in the study of marine symbioses. Although it has long been known that many highly integrated symbiotic partnerships between microorganisms and eukaryotic hosts exist in the marine environment, the specificity, diversity, and biological function of these relationships have often remained obscure. Whether the symbionts reside externally (epibiont) or actually within host cells (cytobiont), they are frequently difficult or impossible to culture free from their host environment. Nucleic acid probing techniques based on ribosomal genes offer the power and resolution necessary to examine aspects of these relationships unapproachable through classical methods.

The earliest application of 16S rDNA sequencing in marine symbiosis sought to examine the phylogenetic relationships of the prokaryotic en-

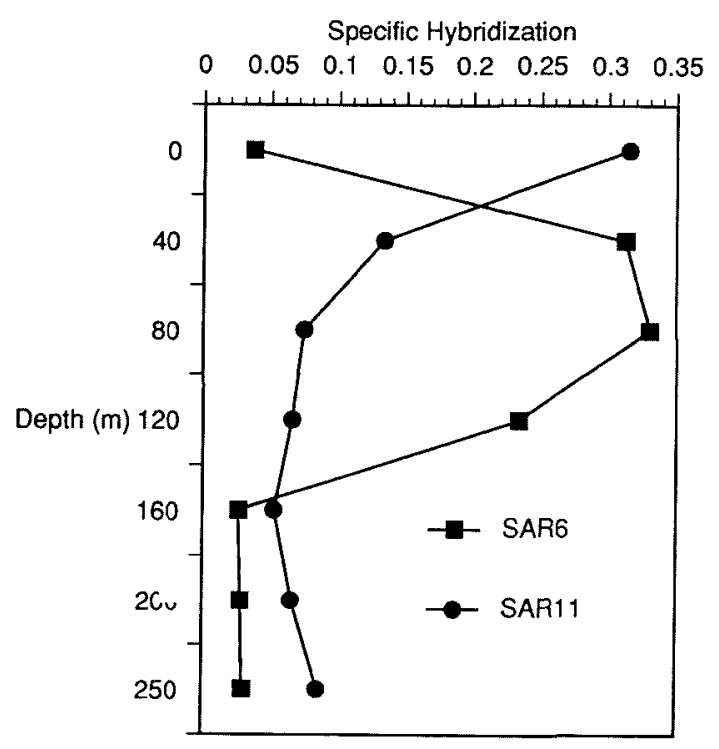

Fig. 5: Ribosomal DNA profiles for BATS35 (Aug 1992). Shown here are the distributions of two gene clusters, $S A R I I(-)$ and prochlorophytes $(S A R 6 ; \square)$. To produce these profiles 16-S rDNAs were amplified from plankton genomic DNA by the polymerase chain reaction using general primers for Bacteria, blotted onto nylon membranes, and hybridized to radioactively labeled probes. dosymbionts found in three invertebrates collected from deep-sea hydrothermal vents (Distel et al., 1988). These studies demonstrated that the vent symbionts form a coherent group that falls into the $\gamma$ subdivision of the purple sulfur bacteria, closely associated with a free-living sulfur-oxidizing bacterium isolated from vent water (Thiomicrospira L-12). In addition, the bacterial symbionts appear to be unique and invariant (monophyletic) within respective host species, suggesting several independent evolutionary origins of the symbiosis. Phylogenetic mapping indicates that symbiont relatedness reflects host relatedness and appears not to be affected by geographic location or habitat variation.

Rowan and Powers (1992) used 16S rDNA sequencing and restriction fragment length polymorphisms (RFLPS) to examine zooxanthella diversity in 22 invertebrate hosts. Zooxanthellae are algal symbionts commonly found in corals. RFLPs are created by using enzymes to cut DNA molecules into fragments, which form characteristic patterns when resolved by chromatography. Rowan and Powers (1992) found six classes of zooxanthellae in a host-specific pattern of distribution. They also discovered that the algal phylogenies were not necessarily congruent with host phylogenetic relationships, suggesting that these symbionts have retained some autonomy and may move laterally between hosts in rare evolutionary events.

In situ hybridization and $16 \mathrm{~S}$ rDNA sequencing have been used to characterize the prokaryotic symbionts of several bivalves and verify the authenticity of cultured isolates. The gill symbionts of shipworms (teredinid mollusks) fix $\mathrm{N}_{2}$ and digest cellulose, apparently enabling their hosts to utilize wood successfully as a food source. In contrast to the results obtained by Rowan and Powers (1992) with zooxanthellae, the symbionts from four separate genera of shipworms were found to be identical, falling within the $\gamma-3$ subdivision of the Proteobacteria (Distel et al., 1991). In sifu hybridization studies using a $16 \mathrm{~S}$ rRNA targeted oligonucleotide specific for the symbiont localized the bacteria to the gill tissue and verified that isolates originally cultured from gill tissue homogenates were the symbionts. The gill symbiont of the bivalve Thyasira flexuosa was reported to be the first endosymbiotic chemoautotroph in culture (Wood and Kelly, 1989). The $16 \mathrm{~S}$ rRNA sequence amplified from the gill and the putative isolate both fall within the $\gamma$ subdivision of the phylum Proteobacteria. However, distance and parsimony analyses clearly grouped the gill sequence closely with other known lucinid gill symbionts and the isolate sequence with the free-living chemoautotroph, Thiomicrospira sp. strain L-12. Thus, sequence comparisons suggest that the isolate was indeed a gill surface contaminant (Distel and Wood, 1992).

One of the most intriguing and yet elusive 


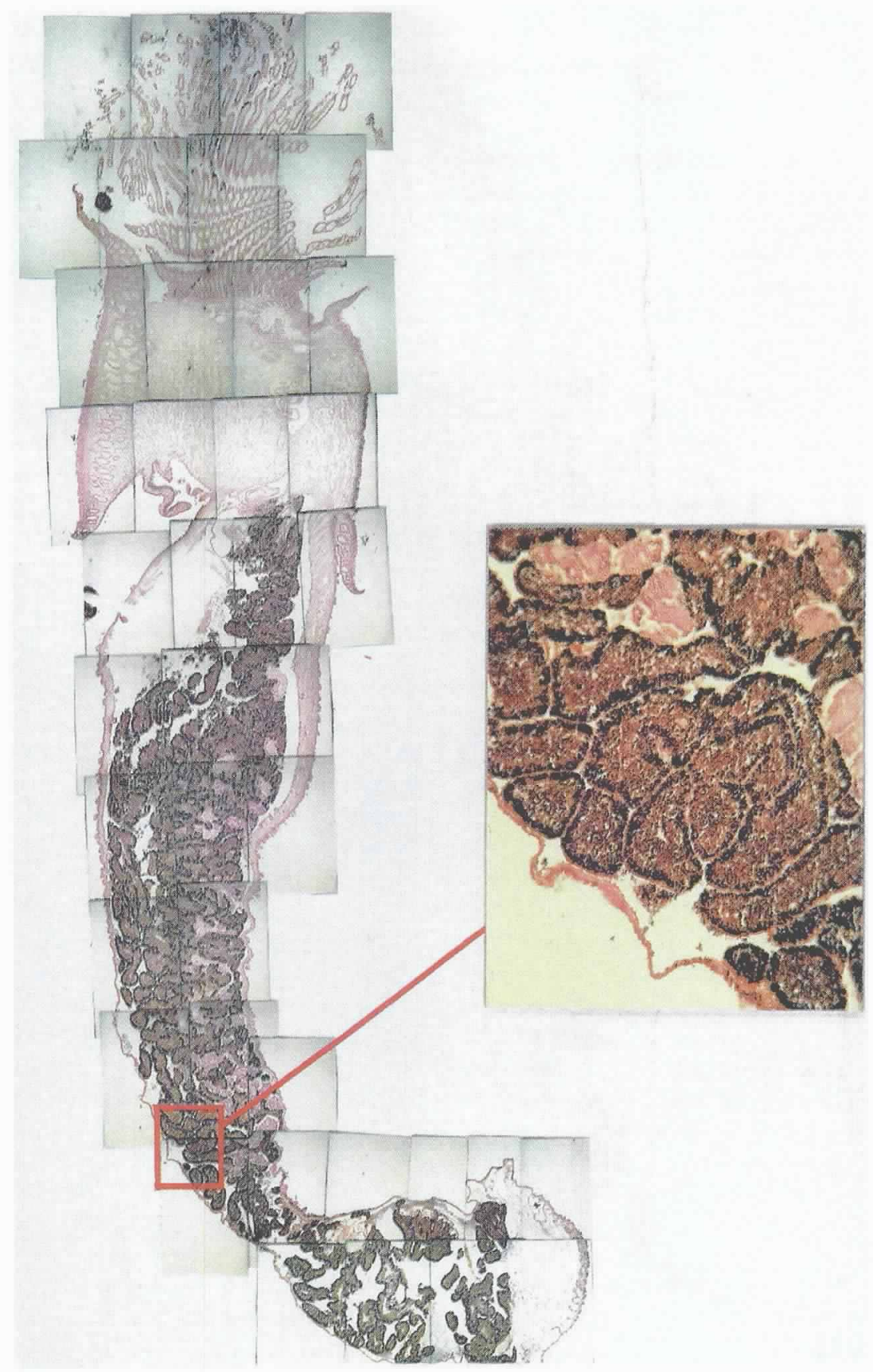

Fig. 6: In situ hybridization to identify symbiont $16 \mathrm{~S} r R N A$ in a whole animal section of the vestimentiferan tubeworm Ridgea piscesae. The vestimentiferan symbiont probe was labeled with a nonradioactive moeity (digoxygenin-UTP) and detected immunocytochemically. The trophosome (trunk region) clearly hybridized to the probe. The lobular nature of the trophosome, with larger bacteria concentrated toward the periphery, results in higher color development near the outside of the lobules (drop out). Reproduced from Cary et al. (1993).

problems in marine symbiosis research is the question of symbiont transmission. By what process are the symbionts acquired by the host and at what stage does the relationship actually become biologically significant? These questions are particularly relevant to endosymbiotic associations where the adult host relies heavily on its symbionts for nutriment. Symbiont transmission can occur vertically (from parent to offspring), horizontally (spread of symbiont between contemporary hosts), or through a direct infection from an environmental stock of microorganisms. Mechanisms of endosymbiont transmission have been successfully addressed only in certain culturable host species (i.e., sponges and tunicates) where the early life stages can be obtained. Approaching 
similar questions in deep-sea organisms is more problematic.

A knowledge of symbiont transmission in hydrothermal vent organisms would affect our interpretations of their reproduction, dispersal, and colonizing strategies. The isolated, ephemeral nature of the vents and the obligate nature of these symbioses suggests transmission strategies that would not leave the inheritance to a chance event. We have designed three oligonucleotide probes specific to each of the symbionts of three vent organisms: the vesicomyid clam Calyptogena magnifica, the vent mussel Bathymodiolus thermophilus, and the vent tubeworm Riftia pachyptila. We have used two approaches to look for vertical symbiont transmission in these vent organisms. The probes are employed as PCR primers for the sensitive detection of symbiont signal $(<1 \mathrm{pg})$ from bulk gonadal DNA extracts of their respective hosts (Cary et al., 1993). The same primers are also used for in situ hybridization experiments to localize the position of symbiont signal in thin sections of host tissues (Fig. 6). To date, these studies have shown that the eggs of the vestimentiferan tubeworms are free of symbionts before spawning and suggest that the bacteria must be acquired at a later time, probably after settlement. This finding suggests that the symbiont must be free-living and possibly culturable. Most recently it has been shown that the ovaries of three species of vesicomyid clams ( $\mathrm{Ca}$ lyptogena spp.) all have amplifiable symbiont signal (Cary and Giovannoni, 1993). Sequence comparisons and RFLP analysis confirm that the signal is identical to that of the symbiont from each respective host. Tissue in situ hybridizations with the symbiont specific oligonucleotides have localized the symbionts to follicle cells surrounding the developing oocytes. thus suggesting a vertical mechanism of symbiont transmission in the vesicomyids.

Our transmission studies are continuing to investigate the ontogenetic and biochemical processes of symbiont inheritance in the gutless protobranch bivalve, Solemya reidi, which also harbors endosymbiotic bacteria in the gill tissue. We plan to advance the probing technology by monitoring the expression of key enzymes to assess the metabolic state of the symbionts during the incorporation process and determine the role of the symbionts in the hosts' early development.

Probably the most impressive of the vent taxa are the tube-dwelling alvinellid polychaetes found inhabiting the hotter areas of active hydrothermal vent chimneys. An individual Alvinella pompejana was recently reported to have survived temperatures in excess of $100^{\circ} \mathrm{C}$ for a prolonged period of time (Chevaldonne et al., 1992). These polychaetes have episymbiotic bacteria intimately associated with modified structures of the host body wall (Gaill et al., 1987). The diversity and role of this epibiotic microflora have not been determined. Currently we are using $16 \mathrm{~S}$ rRNA sequence analysis to examine the diversity of this population. and we hope to derive some indication of the function of this unique assemblage.

\section{Other Applications of rRNAs to Marine Science}

Fluorescently labeled oligonucleotide probes for rRNAs are now being used widely for the detection of single microbial cells by microscopy and flow cytometry (DeLong et al., 1989; Amann et al., 1990a,b). Cell biologists refer to this method as in situ hybridization, referring to the fact that the hybridization reaction actually takes place inside intact cells that have previously been preserved in formaldehyde. This method can be used to identify single cells and also to reveal their growth status, because the fluorescence of hybridized probes is a function of cellular ribosome content (Kerkoff and Ward, 1993; Kemp et al., 1993; Lee and Kemp in press). One of the most interesting results from this work so far has been the observation by Kemp and co-workers that a significant proportion of bacterial cells in coastal plankton populations are inactive. This approach has been applied to the identification of cellulolytic bacteria in shipworms, the identification of planktonic flagellates, and the measurement of cellular growth rates in biofilms (Distel et al., 1991; Lim et al., 1993; Poulsen et al., 1993). Another area of active research with fluorescent oligonucleotide probes for rRNAs is their application to the detection of sulfate-reducing bacteria. These probes in particular are promising tools for the exploration of benthic microbial processes, biofilms, and anaerobic microenvironments (Devereaux et al., 1992).

Uses of rRNAs for the identification of genetically distinct phytoplankton populations are being explored. Scholin and Anderson (1993) report that hypervariable regions of the large subunit rRNAs (28S rRNAs) of the dinoflagellate Alexandrium can be used to discriminate between closely related regional populations of strains and species. The data are providing evidence of the recent dispersal of toxic strains from North America to Japan. Similar genetic studies, relying on the most variable regions of rRNAs, are likely to be useful in resolving other plankton population biology questions. This will be particularly true in cases such as larval forms where morphological characters are not useful for identification.

Internal transcribed spacers (Fig. 1) are being used to address biogeographical questions that require the resolution of relatively recent evolutionary events. Maternally inherited DNA, such as plastid ITS regions, are particularly useful for this purpose. This technique has been applied to the macrophytic algae Cladophoropsis. Gracilaria, and Gracilariopsis (Goff et al., in press; Kooistra et al., 1992). 


\section{Some Limitations of Ribosomal RNAs}

Although molecular phylogeny may reveal insights into the physiology of organisms, it does not provide direct information on the actual or potential biogeochemical activity of organisms. For these purposes, markers for functional genes, such as nitrogenase, nitrite reductase, and RUBP carboxylase, are more useful. In the case of bacterioplankton known only by their rDNA markers, it will be necessary eventually either to grow the organisms or to develop methods for establishing genetic linkage between functional genes and rDNA markers in mixtures of genomic DNA. Ultimately, it is the distributions and activities of bacterioplankton that are of key interest to oceanographers.

\section{Conclusion}

It is apparent that in years ahead rRNAs will be a mainstay of molecular investigations in biological oceanography. Their role as phylogenetic markers for investigating plankton populations dynamics is just beginning to be explored. The continued use of rRNAs as a tool for dissecting complex symbiotic associations is assured. Perhaps most important, rRNAs have been a proving ground for developing conceptual approaches in molecular evolution and molecular microbial ecology. In this regard, we may see many of the experimental approaches first developed with rRNAs applied to a variety of macromolecules in the future.

\section{Acknowledgements}

We are grateful to Katharine Field for advice and suggestions and to Nanci Adair for technical assistance. We also acknowledge the cooperation of the Bermuda Biological Station for Research, the crew of the RV Weatherbird II and the Bermuda Atlantic Time Series team. This work was supported by NSF grants OCE-9016373 to S.J.G. and OCE-8915305 and OCE-9217950 to S.C.C.

\section{References}

Amann, R.I., B. Bender, R.J. Olsen, S.W. Chisolm, R. Devereux and D.A. Stahl, 1990a: Combination of $16 \mathrm{~S}$ rRNA-targeted oligonucleotide probes with flow cytometry for analyzing mixed microbial populations. Appl. Environ. Microbiol., 56, 1919-1925.

Amann, R.I., L. Krumholz, and D.A. Stahl, 1990b: Fluorescent-oligonucleotide probing of whole cells for deerminative, phylogenetic and environmental studies in microbiology. J. Bacteriol.. 172. 762-770.

Azam, F.. T. Fenchel, J.G. Field, J.S. Gray, L.A. Meyer-Reil, and F. Thingstad, 1983: The ecological role of watercolumn microbes in the sea. Mar. Ecol. Prog. Ser. 10, $257-263$

Brand, L.E.. 1987: Nutrition and culture of autotrophic picoplankton and ultraplankton. Can. Bull. Fish. Aquat. Sci., 214, 205-233.

Britschgi, T.B and S.J. Giovannoni, 1991: Phylogenetic analysis of a natural marine bacterioplankton population by rRNA gene cloning and sequencing. Appl. Environ. Microbiol., 57, 1313-1318
Brosius, J., T.J. Dull. D.D. Sleeter, and H. Noller, 1981: Genc organization and primary structure of a ribosomal RNA operon from Escherichia coli. J. Mol. Biol., 148, 107-127.

Campbell, L., E.J. Carpenter, and V.J. Iacono. 1983: Identification and enumeration of marine chroococcoid cyanobacteria by immunofluorescence. Appl. Environ. Microbiol., 46, 553-559.

Cary, S.C. and S.J. Giovannoni, 1993: Transovarial inheritance of endosymbiotic bacteria in vesicomyid clams found inhabiting deep-sea hydrothermal and cold vent systems. Proc. Natl. Acad. Sci. USA, 90, 5695-5699.

Cary, S.C., W.D. Warren, E. Anderson, and S.J. Giovannoni. 1993: Identification and localization of bacterial endosymbionts in hydrothermal vent taxa with symbiontspecific PCR amplification and in situ hybridization techniques. Mar. Mol. Biol. Biotech., 2, 5l-62.

Chevaldonne, P., D. Desbruyeres, and J.J. Childress. 1992: Some like it hot, some like it hotter. Nature. 359. $593-594$.

Devereux. R., M.D. Kane, J. Winfrey, and D. Stahl, 1992: Genus- and group-specific hybridization probes for determinative and environmental studies of sulfate-reducing bacteria. Syst. Appl. Microbiol., 15, 601-609.

DeLong, E.F., G.S. Wickham. and N.R. Pace. 1989: Phylogenetic stains: ribosomal RNA-based probes for identification of single cells. Science. 243. 1360-1363.

DeLong, E.F., 1992: Archaea in coastal marine environments. Proc. Natl. Acad. Sci. USA, 89, 5685-5689.

DeLong. E.F., D.G. Frank, and A.L. Alldridge, 1993: Phylogenetic diversity of aggregate-attached vs. free-living marine bacteria assemblages. Limnol. Oceanogr., 38. 924-934.

Distel, D.L. and A.P. Wood. 1992: Characterization of the gill symbiont of Thyasira flexuosa (Thyasiridae: Bivalvia) by use of polymerase chain reaction and $16 \mathrm{~S}$ rRNA sequence analysis. J. Bacteriol., I74, 6317-6320.

Distel, D.L., D.L. Lane, G.J. Olsen. S.J. Giovannoni. B. Pace, N. Pace, D. Stahl, and H. Felbeck, 1988: Sulfur-oxidizing bacterial endosymbionts: analysis of phylogeny and specificity by $16 \mathrm{~S}$ ribosomal RNA sequences. J. Bacteriol., J70. 2506-2510.

Distel, D.L., E.F. DeLong, and J.B. Waterbury. 1991: Phylogenetic characterization and in situ localization of the bacterial symbiont of shipworms (Teredinidae: Bivalvia) by using $16 \mathrm{~S}$ rRNA sequence analysis and oligodeoxynucleotide probe hybridization. Appl. Environ. Microbiol. 57. 2376-2382.

Falkowski, G., and J. LaRoche, 1991: Molecular biology in studies of ocean processes. Inter. Rev: Cytol., I28. 261-303

Ferguson. R.L.. E.N. Buckley, and A.V. Palumbo, 1984: Response of marine bacterioplankton to differential filtration and confinement. Appl. Environ. Microbiol., 47, 49-55.

Fuhrman. J.A.. K. McCallum, and A.A. Davis, 1992: Novel major archaebacterial group from marine plankton. $\mathrm{Na}$ ture, 356, 148-149.

Fuhrman, J.A., K. McCallum, and A.A. Davis. 1993: Phylogenetic diversity of subsurface marine microbial communities from the Atlantic and Pacific oceans. Appl. Environ. Microbiol. 59, 1294-1302.

Gaill, F., D. Desbruyeres, and D. Prieur, 1987: Bacterial communities associated with the "Pompeii worms" from the East Pacific Rise hydrothermal vents. SEM, TEM observations. Microb. Ecol., 13, 129-139.

Giovannoni, S.J., E.F. DeLong. T.M. Schmidt, and N.R. Pace, 1990: Tangential flow filtration and preliminary phylogenetic analysis of marine picoplankton. Appl. Environ. Microbiol., 56, 2572-2575.

Giovannoni, S.J.. E.F. DeLong. G.J. Olsen, and N.R. Pace. 1988: Phylogenetic group-specific oligodeoxynucleotide probes for the identification of single microbial cells. $J$. Bacteriol., 170, 720-726. 
Goff, L.J., D.A. Moon. and A.W. Coleman, in press: Molecular delineation of species in the red algal agarophytes (Gracilareales). J. Phycol.

Hollibaugh, J.T., 1988: Limitations of the thymidine method for estimating bacterial production due to thymidine metabolism. Mar. Ecol. Prog. Ser., 43, 19-30.

Huber, R., P. Stoffers, J.L. Cheminee, H.H. Richnow, and K.O. Stetter, 1990: Hyperthermophilic archaebacteria within the crater and open-sea plume of erupting Macdonald Seamount. Nature, 345, 179-182.

Kemp. P.F., S. Lee, J. LaRoche, 1993: Estimating the growth rate of slow-growing marine bacteria from RNA content. Appl. Environ. Microbiol. 59, 2594-2601.

Kerkhof, L. and B.B. Ward, 1993: Comparison of nucleic acid hybridization and fluorometry for measurement of the relationship between RNA/DNA ratio and growth rate in a marine bacterium. Appl. Environ. Microbiol., 59, 1303-1309.

Kogure, K., L. Simidu, and N. Taga, 1979: A tentative direct microscopic method for counting living marine bacteria. Can. J. Microbiol., 25, 415-420.

Kooistra, W.H.C.F., W.T. Stam. J.L. Olsen, and C. VandenHoek, 1992: Biogeography of Cladophoropsis membranaceae [Chlorophyta] based on comparisons of nuclear rDNA ITS sequences. $J$. Phycol., 28, 660-668.

Lee, S.H. and J.A. Furhman, 1990: DNA hydridization to compare species composition of natural bacterioplankton studied at the level of community DNA. Appl. Environ. Microbiol. 56, 739-746.

Lee, S. and P.F. Kemp, in press: Single-cell RNA content of natural marine planktonic bacteria measured by hybridization with multiple $16 \mathrm{~S}$ rRNA-targeted fluorescent probes, Limnol. Oceunogr.

Lim, E.L., L.A. Amaral, D.A. Caron, and E.F. DeLong. 1993: Application of rRNA probes for observing nanoplanktonic protists. Appl. Environ. Microbiol. 59, 1647-1655.

Olsen, G.J., N. Larson, and C.R. Woese, 1991: The ribosomal RNA Database project. Nucleic Acids Res., 19(Suppl.), 2017-2021.

Olsen. G.J.. D.L. Lane, S.J. Giovannoni, N.R. Pace, and
D.A. Stahl. 1986: Microbial ecology and evolution: a ribosomal RNA approach. Ann. Rev. Microbiol., 40. 337-366.

Poulsen, L.K.. G. Ballard, and D.A. Stahl. 1993: Use of rRNA flouresence in situ hybridization for measuring the activity of single cells in young and established biofilms. Appl. Environ. Microbiol. 59, 1354-1360.

Rappé, M.S., N.L. Fowles, and S.J. Giovannoni, 1993: Identification of a novel 16S rRNA lineage of the Chloroflexux/Herpetosiphon phylum in Sargasso Sea bacterioplankton. Abstr. American Society of Limnology and Oceanography Annual Meeting. Edmonton, Canada.

Rowan. R. and D.A. Powers, 1992: A molecular genetic classification of zooxanthellae and the evolution of animals. Science, 25I, 1348-1351.

Rozak, D.B. and R.R. Colwell, 1987: Survival strategies of bacteria in the natural environment. Microbiol. Rev.. $51,365-379$.

Schmidt. T.E.. E.F. DeLong, and N.R. Pace, 1991: Analysis of a marine picoplankton community by $16 \mathrm{~S}$ rRNA gene cloning and sequencing. J. Bacteriol., 173, 4371-4378.

Scholin. C.A. and D.M. Anderson, 1993: Population analysis of toxic and non-toxic Alexandrium species using ribosomal RNA signature sequences. In: Toxic Phytoplankton Blooms in the Sea. T.J. Smayda and Y. Shimizu. eds., Elsevier, Amsterdam. 95-102.

Stahl, D.A., B. Flesher. H.W. Mansfield, and L. Montgomery. 1988: Use of phylogenetically-based hybridization probes for studies of ruminant microbial ecology. Appl. Envirnn. Microbiol., 54, 1079-1084.

Urbach, E., D. Robertson, and S.W. Chisholm, 1992: Multiple evolutionary origins of prochlorophytes within the cyanobacterial radiation. Nature, 355, 267-270.

Woese, C.R., 1987: Bacterial evolution. Microbiol. Rev.. 51, 221-271.

Wood, A.P. and D.P. Kelly, 1989: Isolation and physiological characterization of Thiobacillus thyasiris sp. nov., a novel marine facultative autotrophic and putative symbiont of Thyasira flexuosa. Arch. Microbiol., I52, $160-166$. 